\title{
Older Children's Responses to Wordless Picturebooks: Making Connections
}

\author{
Lina Iordanaki ${ }^{1,2}$ (D)
}

Accepted: 12 September 2020 / Published online: 19 October 2020

(c) The Author(s) 2020

\begin{abstract}
This article explores 11-year-old children's connections to prior knowledge and experiences while reading a wordless version of Little Red Riding Hood. The study extends pre-existing research on reader response theories by focusing on images instead of written text. The approach taken places emphasis on the reader's active engagement, for readers use visual decoding skills and culturally oriented knowledge in an effort to interpret the wordless story and fill its gaps. A multiple case study design was implemented involving sixteen students from Greece and England, all being in the final year of primary school and identified as fluent readers. The participants in each country, separated into two groups of four, read the book in an empty classroom, with no teacher intervention. The aim was to identify patterns in their unmediated responses, and to present and analyse the themes of their connections based on empirical evidence. The participants linked the illustrations to their common general knowledge, including cultural references and gender-based generalisations, to personal experiences, and to other texts such as books and films. The findings reveal the prevalence of common themes in their interpretations of the story and encourage engagement with wordless picturebooks, even for older students. Due to their special nature and complexity, these books can initiate interesting conversations on issues such as identity and gender diversity.
\end{abstract}

\footnotetext{
Lina Iordanaki completed her PhD at the Faculty of Education, University of Cambridge, UK. She has worked in Greek and English schools and has participated in several education conferences and programmes. In 2016, she joined the committee of the International Board on Books for Young People (IBBY) UK and since then, she has written various book reviews, blog posts and articles. Her research interests lie in picturebooks, graphic novels, literacy, poetry for children, and digital education. She is currently working for the Institute of Education at University College London.
}

Little Red Riding Hood-Perrault, Charles and Perles, Pedro. (2010). Caperucita Roja. Alcalá la Real: Mil y un Cuentos.

Lina Iordanaki

1.iordanaki@ucl.ac.uk

1 University of Cambridge - Faculty of Education, Cambridge, UK

2 University College London - Institute of Education, London, UK 
Keywords Wordless picturebooks $\cdot$ Reader response $\cdot$ Connections $\cdot$ Intertextuality

\section{Introduction}

Wordless picturebooks tell their stories through illustrations without the aid of print. Surprisingly, even though there is much to say about picturebooks in general and how children engage with them, academic interest in wordless picturebooks has been sparked only during the last decades. Many researchers in the field (Arizpe, Colomer \& Martinez-Roldán, 2014; Crawford \& Hade, 2000; Pantaleo, 2009; Serafini, 2014a) have pointed out the potential of wordless picturebooks for multiple interpretations and there have also been efforts to use them for supporting children's narrative and linguistic skills. Studies conducted on pre-reading children have shown that wordless picturebooks have positive effects with respect to emergent literacy (Lindauer, 1988; Lysaker, 2006, 2019; Lysaker \& Miller, 2013; Reese, 1996) which highlights them as a very helpful tool for new readers; however, there is room for research and discussion with regards to an older audience, especially to proficient readers of verbal texts.

A limited number of studies involves children older than nine-years-old, all conducted in a different context from the research described in this article. For example, Evelyn Arizpe et al. (2014) work with multi-ethnic classrooms to support immigrant children's literary understanding and visual literacy. Fiona Maine, in collaboration with schools in nine countries, leads the DIALLS project which investigates cultural literacy and how children make sense of Europe (Maine, Cook \& Lähdesmäki, 2019). Sylvia Pantaleo examines wordless books with a focus on postmodern characteristics in picturebooks (Pantaleo, 2007a). In all the above examples, the children read the books with the help of teachers-or 'mediators' (Arizpe et al., 2014) — who participate in the read-aloud by using prompts, asking questions and encouraging children's engagement. The research presented in this article gives a voice to children's unmediated responses, since no adults joined their discussions. Giving children the freedom to express themselves and make their own connections can offer insights about how they infer meaning during the reading process and can provide useful information to teachers who usually share texts with them.

The study informing this paper was conducted as part of my $\mathrm{PhD}$ research at the University of Cambridge (Iordanaki, 2017). It brings together traditional reader response theories and the relatively new field of wordless picturebooks with the purpose of exploring 11-year-old children's connections while reading wordless picturebooks with no adult intervention, in two different contexts: Greece and England. Using empirical evidence, this research reinforces the idea that wordless picturebooks could intrigue not only very young children, but also fluent readers. The removal of the linguistic barrier gives the opportunity to explore the same illustrations with groups from two different countries and to identify patterns in their responses. 


\section{Filling the Visual Gaps}

Wolfgang Iser (1980) demonstrates the ambiguity of literature and the active role of the reader, suggesting that texts are infused with gaps, or unexplained areas, which the reader is called on to fill during the meaning-making process. Prominence is given to the active participation of the reader, but it should not be overlooked that the text on which the reader draws determines to a great extent the level and the quality of this engagement. Louise Rosenblatt's transactional theory (1978/1994) emphasises the reciprocal, mutually defining relationship between the reader and the literary text; "a relationship with, and continuing awareness of, the text" (p. 29). The reader fills the gaps of the text, but the text provides those gaps. A promising text that features a variety of details could evoke multiple valuable responses.

Wordless picturebooks are a fine example of promising text-in Rosenblatt's broad sense of text-infused with multiple illustrative details. Images give visual cues and include gaps for the critical beholder to fill. "The cues that will guide the reader are the sign-maker's selection and use of the various affordances of the mode of image" (Pantaleo, 2013, p. 132). On his official website, artist Shaun Tan (2004) refers to the readership of picturebooks and his concern as a creator to always involve the reader in the meaning-making process. More specifically, he mirrors Iser's gaps (1980) by explaining that he presents "unfinished" stories to his readers, so that they can actively engage in completing them with their thoughts.

Due to the polysemic nature of wordless picturebooks, children act as co-authors of the visual story (Serafini, 2014a, b). These texts can be considered as what Roland Barthes (1974, p. 4) calls "writerly texts" as they promote the active participation of the reader in contrast to "readerly texts", the meanings of which are considered fixed and pre-determined. This can be neatly linked back to Iser's words (1980, pp. 84-85): "If the text reproduces and confirms familiar norms, the reader may remain relatively passive, whereas he is forced into intensive activity when the common ground is cut away from under him". In the case of wordless picturebooks, words and the prevalence of one unequivocal answer are the main common grounds cut away under the reader. Thus, wordless picturebooks can trigger a plethora of reading transactions.

\section{Research Context}

My research design involved multiple case studies of children in the chosen age group and contained comparative elements. The research was conducted at an English state primary school in the East of England and a Greek private primary school in Athens; both schools of similar size (approximately 350 students). The sample consisted of sixteen 11-year-old children (eight in each country), all born and raised in the country where their school was based. Their responses were 
recorded but pseudonyms were used in the transcription to provide anonymity. The participants were organised into four groups of four (two English and two Greek groups) as they were expected to more naturally articulate their thoughts in this way. The dynamics in a group reading discussion can determine the interpretation of a text, as each member expresses their views, listens to the ideas of the others, argues and perhaps alters their opinion based on the dialogue. In an effort to maintain gender balance, all groups consisted of two girls and two boys, except for English Group 1, the members of which were three girls and a boy. To ensure the eligibility of the sample, I spent approximately 1 month working voluntarily as a teaching assistant in the schools of the case studies. The teachers of each class assisted in the selection by helping me identify proficient readers of verbal texts and by giving me an overview of the pupils' limited experience in discussing images at school.

From more than 100 wordless picturebooks that I encountered during the design of this study, I chose four with potential for greater analysis. In this article, I limit myself to presenting only the first book, the wordless version of Charles Perrault's Little Red Riding Hood, Caperucita Roja, illustrated by Pedro Perles (2010). It follows the traditional fairytale with whimsical pictures in which the sizes of the heroes are distorted. For instance, Little Red Riding Hood is depicted as a tiny figure, whereas her mother and the wolf look gigantic in comparison. New elements are introduced, such as the red shoe of the main character first depicted on the wolf's leg on the front cover, and then abandoned on the grass on the last scene of the book. The indeterminate ending leaves the fate of Little Red Riding Hood and her grandmother uncertain. Taking advantage of the absence of words, the selected book was not subject to linguistic restraints and was used in the same manner at both schools. The Spanish title, however, was not translated into the children's language to present one more puzzle to be solved. The book was given to the participants with the only instruction being to read it aloud with the classmates of their group at their own pace and to make any comments they wish as their teacher and the researcher would not be involved in their reading process.

Throughout the whole study process, I acknowledge that each pupil is different, each reading is situational, and given the small data set, any generalisations should be tempered with caution. Bassey's idea of fuzzy generalisations (1999) is embraced in this research; case studies might lead to empirical findings which are likely to (but not definitively) be relevant in similar research contexts. Additionally, my socio-cultural background differs from the English children's not only in terms of age and previous experiences, but also in terms of nationality. This affects my reading and, in turn, my interpretation of the data. However, it does not affect the accuracy or the completeness of the data analysis. As I have been a UK resident for several years, I have benefitted from discussions regarding the veracity of my dataset with UK academics and researchers in the field of education. 


\section{Making Connections}

Visual literacy skills, which provide the reader with the metalanguage to talk about colours, frames and other visual elements (Kress \& van Leeuwen, 2006), are essential for analysing the plot of wordless picturebooks and for answering more impersonal questions, such as predictions and comments on the illustrator's techniques. However, aesthetic engagement can be achieved through personal responses, "cultural, social and personal" stories (Rosenblatt, 1994, p. 1064), stimulated during the reading process. Although a reader "must decipher the images or concepts or assertions that the words point to [efferent stance], he also pays attention to the associations, feelings, attitudes, and ideas that these words and their references arouse within him [aesthetic stance]" (pp. 24, 25).

Rosenblatt mentions the aesthetic stance in almost every one of her published works; she reflects on past transactions in life and language, ideas, associations, attitudes, private feelings and sensations, but does not delve in depth into them. All the above could be separated into two general categories: associations stemmed from readers' prior knowledge and experience, and readers' emotions and preferences. For the purpose of this article, I focus on the first category.

Although there are different approaches in the general realm of reader response theories, most of them embrace the importance of the reader's previous knowledge and experience. Recalling obtained knowledge and life-to-text experiences (Sipe, 2008a) implies that the reader is not passive during the meaning-making process. Each reader brings to the text their own knowledge, thoughts, preoccupations and past experiences; all of them compound their "mnemonic baggage" (Rosenblatt, $1965 / 1995$, p. 55) which is necessary for an aesthetic experience. Similarly, Rosenblatt (1991) mentions readers' "reservoir". "The reader brings to the text a reservoir of past experiences with language and the world. If the signs on the page are linked to elements in that reservoir, these linkages rise into consciousness" (p. 445). Both the Greek and the English groups resort to this reservoir of prior knowledge and experiences to make sense of the wordless picturebook Caperucita Roja. The absence of words gives them freedom to make a variety of connections, of which some are explicitly related to the story of the book, and others more subtle. The themes that emerged are connections to their common general knowledge, personal and intertextual references, all discussed in detail in the following subsections.

\section{Common General Knowledge}

A socio-cultural perspective highlights that each person perceives the world in a culture-bound and hence different way. There is no one context-free universal truth and in turn, the knowledge that refers to the world can be different for each person (John-Steiner \& Mahn, 1996, Thomas, 2013). However, there is a general springboard of knowledge which makes human communication possible. This is common general knowledge, the so-called "world knowledge". It is "the individual's knowledge of the world" that can be widely shared and accessed (Tennent, 2010, p. 39) and it can serve as common ground of communication between the members of each group. It 
is difficult to identify the accuracy, quality or the origins of this knowledge. As it is often just "known", it might be based on education or on informal sources, such as daily experiences or word-of-mouth communication. In this article, world knowledge is replaced by the term "common general knowledge" to highlight its shared and joint aspect and to separate it from certain knowledge within a specific field.

Firstly, in order to make meaning from the pictures, the children in this study identify what they see and connect it to the storehouse of their everyday experience, as Barthes' cultural/referential code indicates (1974, p. 20). Perry Nodelman (2005, p. 129) highlights: "I must have a pre-existing knowledge of actual objects to understand which qualities of representations [...] do resemble those of represented objects, and which [...] are merely features of the medium or style of representation, and therefore to be ignored". Hence, the children look closely at the illustration for the visual counterparts of objects and places that are familiar to them. For example, when they encountered the black threatening furry figure, they immediately recognised the wolf. By recalling and at the same testing, or "cross-checking" (Lysaker \& Hopper, 2015 , p. 655) their common general knowledge, the children try to gain a better understanding of the story characters. Drawing on their knowledge of wolves, Peter and Lea from English Group 2 try to justify the wolf's actions. According to them, the wolf did not attack Little Red Riding Hood without a reason. His instinct of survival or hunger (Peter: 'I think the wolf's hungry, because wolves don't usually eat people”) and self-defence (Lea: “it's just means of protection"), must have led him to do so.

\section{Cultural Traditions}

Cultural traditions can be included in the broad category of common general knowledge, as they are usually incorporated into children's lives, affect the children's perception of the world and typically nurture their sense of culture. The children in this study occasionally refer to customs. When English Group 1 reads the fourth doublespread of Caperucita Roja (Fig. 1), the children talk about the brown marks that look like flowers on the ground:

[English Group 1]

Jenny: I think there's like flies -

Rita: They're flowers, aren't they?

Albert: It looks like leaves.

Rita: They're dropping flowers.

Albert: Like dead leaves.

Jenny: No, they're like those things that when you..., it marks yellow on you.

Dandelions.

Albert: Oh yeah.

Ophelia: Or like pollen.

Albert: Especially that one there looks like one.

Jenny: Yeah that's what I think.

Albert: Where it gives like if you like butter or whatever it is.

Ophelia: Buttercup. 


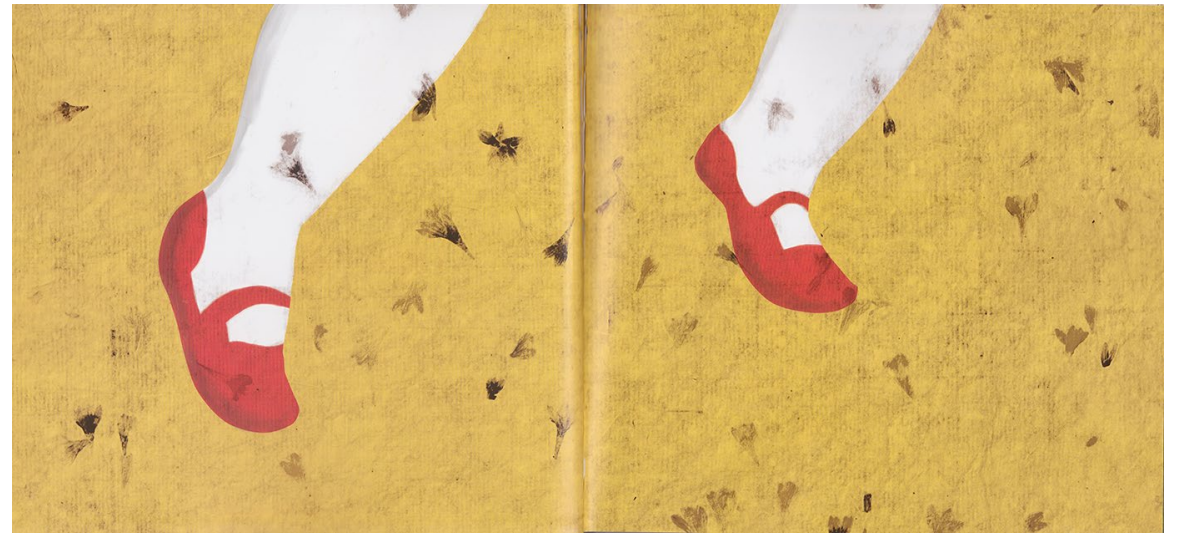

Fig. 1 Caperucita Roja, Doublespread 4. Description: A pair of legs with red ballet pumps on a yellowish grass with scattered black leaves/flowers (Colour figure online)

Although this is a shared cultural influence between the children in this group, as a non-English person, I had to search for more information to understand their discussion. According to folk tradition, people hold buttercup flowers under the chin of someone they know. If the yellow reflection from the petals is still obvious under the chin, then this means that the person likes butter.

Apart from very few examples of connections to country-specific customs, the findings indicate that these children's culture-related responses present many similarities. There are cases in which the groups talk about more universal traditions, symbolisms and common superstitions relevant to both England and Greece. For instance, in case of the white handkerchief that Little Red Riding Hood's mother waves when the girl leaves home to visit her grandmother, English group 2 associates the white piece of cloth with a sign of surrender during war or with a gift of love in medieval ages.

Another more global topic of discussion explored by all groups is fairytales. The children's familiarity with fairytales is obvious from the following extract in which English Group 2 explains how they know the story of Little Red Riding Hood:

[English Group 2]

Maria: It's quite a known -

Lea: Fairytale.

Maria: Yeah.

Lea: It's like most people do it at school. They learn about like fairytales and things.

Darren: Yeah we did it in Year 1 and so has my brother done it in Year 1.

Peter: My brother, my youngest brother used to have all the like Little Red

Riding Hood, the Three Bears -

Darren: Yeah I have the book at home.

Maria: I have a Japanese book of Little Red Riding Hood. 
Darren: I have the book of the most common fairytales and there's like Little

Red Riding Hood ((overtalking)) -

Lea: Like do you know the story of the Gingerbread Man?

Darren: Yeah, I do.

Lea: And like the Cinderella story. It's just a known -

Maria: And like Snow White and like common fairytales.

Lea: But Cinderella and Snow White are Disney films.

Darren: No but they're also fairytales. Just they're made into Disney films.

At the beginning of this conversation, the children focus on school and how they read these stories at a younger age. Peter's personal connection regarding his brother's collection of books encourages his classmates to talk about the fairytales they have at home and to give more examples. In the end, Lea repeats Maria's words ("It's just a known [fairytale]"), implying that the foundations of their knowledge had been grounded so long ago in the past that they do not remember exactly when, where and how. Fairytales are mostly seen as part of oral tradition, of knowledge acquired before the children were able to read. Lea, however, mentions that Cinderella and Snow White are Disney films. Her comment is followed by Darren's correction; these are tales later "made into Disney films". The success and popularity of these films overshadow the original tales in Lea's mind. In a very similar way, Christiana from Greek Group 1 explains to her classmates "she had known Little Red Riding Hood before she turned into a cartoon". Since film and associated merchandise made fairytales cross national borders, these stories tend to present a common ground for communication, "a shared cultural heritage" (Ghosh, 2015, p. 221), which transcends traditional inter-personal, inter-generational and inter-cultural boundaries.

\section{Gender Stereotypes}

Common general knowledge also includes stereotyping, that is, making assumptions about how particular groups might be expected to look, think and behave. The children's surrounding environment affects their notion of the world, of how things "should be" and how people "should" behave. In the group discussions of this study, gender was the most discussed topic that raised various stereotypical reactions.

Thomas Crisp and Brittany Hiller (2011, p. 196) explore "sex-role representation" on Caldecott medal-winning picturebooks, among which there are other wordless and nearly wordless picturebooks, such as Tuesday (Wiesner, 1991), Flotsam (Wiesner, 2006) and The Lion and the Mouse (Pinkney, 2009). They recognise that these books' ambiguity offer many opportunities to shape various views on topics such as gender, that might seem to be infused with more ingrained beliefs:

these books depict human or non-human characters that may appear for some readers to be culturally coded as either male or female, but because there are minimal [or no] words in the text, these images often allow spaces in which any reader may look at and identify a character as being 'like' themselves or someone they know - regardless of biological sex or gender (Crisp and Hiller, 2011, p. 204). 


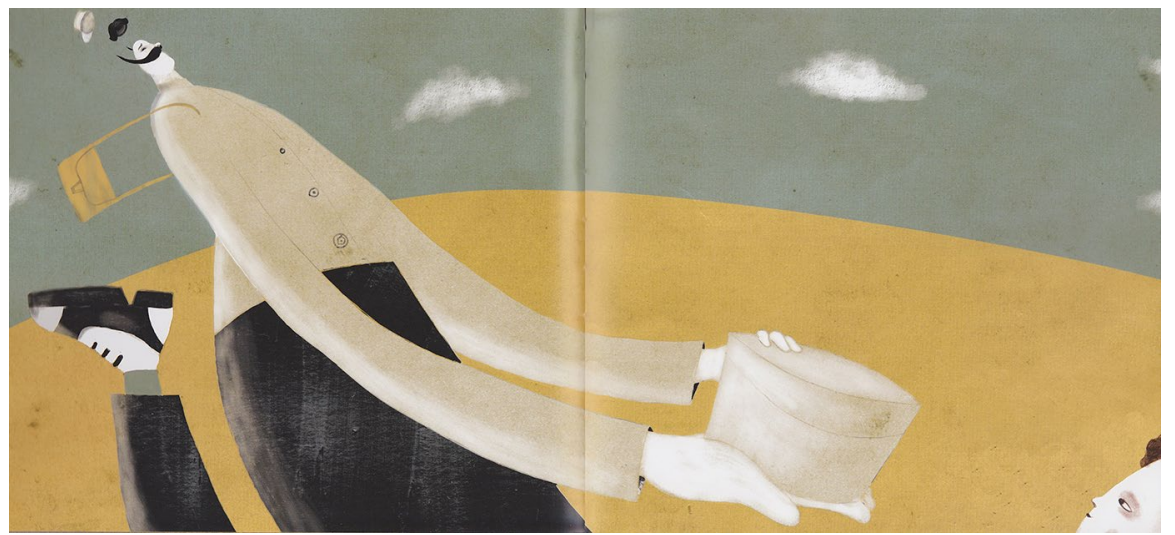

Fig. 2 Caperucita Roja, Doublespread 2. Description: The postman (disproportioned, tiny head, big body, long arms) is offering a box to a little person that is Little Red Riding Hood, whose face is hardly visible on the bottom right corner of the page. The postman has a long moustache and is also carrying a bag on his shoulder (Colour figure online)

This space that Crisp and Hiller refer to is reminiscent of Iser's gaps (1980), in that they function in the same way, inviting readers to fill them with their meaningmaking. The children of this study look for cultural and social implications in an attempt to identify the gender of the distorted figures. They observe the clothing and the accessories which can also convey cultural nuances. For instance, when Angeliki first sees the doublespread with the postman (Fig. 2), she thinks that the postman is a girl, but the rest of the group disagree:

[Greek Group 2]

Angeliki: He [the postman] is carrying a bag. Is it a girl maybe?

Kimon: No.

Angeliki: Yes, but look at how [he] lifts the leg.

Kimon: Probably because he is very happy.

Eleni: He also has a moustache.

Angeliki: And? Conchita also has a moustache! (Angeliki and Kimon laugh).

According to Angeliki, holding a bag is more common for women. Also, the way that the postman lifts his leg seems feminine to her. Even the moustache that the character has does not change her opinion, because she recalls Conchita Wurst, the winner of the 2014 Eurovision Song Contest, who is a man dressed as a woman with his face unshaved. The Eurovision Song Contest is a well-known event to Greeks, and Conchita's victory courted much controversy in the national press and media. It is not surprising, therefore, that Angeliki and her classmates share the same cultural expectations. What is noteworthy, however, is that Angeliki recalls Conchita to suggest that a moustache is not necessarily a gender trait, though at the same time the children respond to it as funny. This argument could have the potential to stimulate a long thought-provoking discussion, especially, perhaps, with the careful guidance of a teacher, on gender and on how people who seem not to belong to the binary 


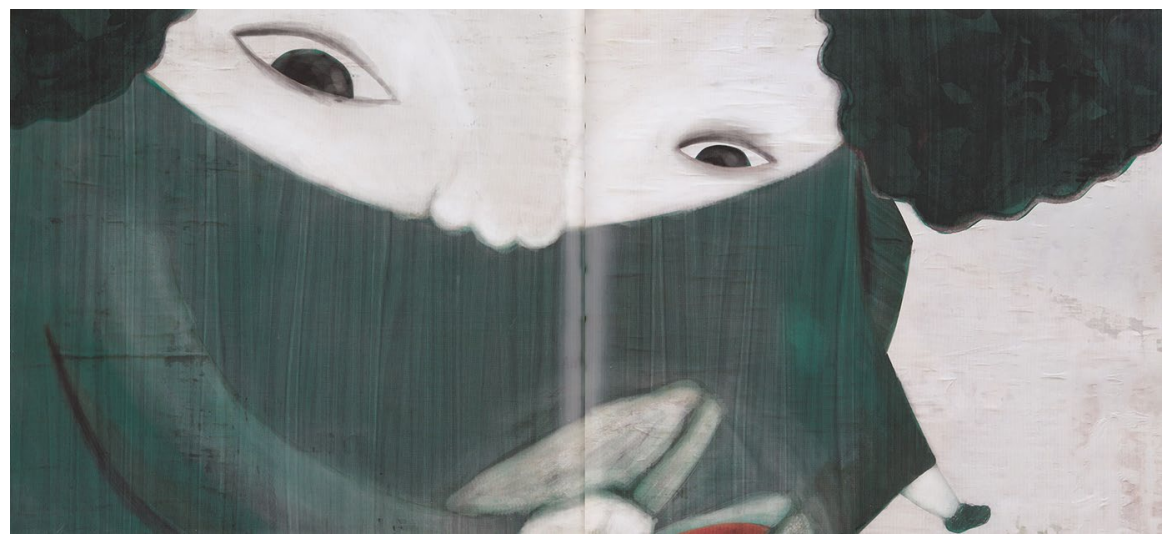

Fig. 3 Caperucita Roja, Doublespread 3. Description: Little Red Riding Hood in a distorted shape (tiny legs, gigantic head) is opening a box (bird's eye view). The picture is in black and white tones and only the content of the box is red (Colour figure online)

categorisations of "male" and "female" figure in children's perceptions. Without any further comments though, Angeliki and Kimon laugh, possibly to avoid deepening the conversation and touching upon a difficult topic, and they move on by turning the page.

Similar to the Greek children, English Group 2 observes the protagonist opening her grandmother's present (Fig. 3) and eagerly turns to Doublespread 4 which depicts the content of the box, namely the red shoes:

\section{[English Group 2]}

Maria: I think this is the boy that was on the page in the corner.

Peter: That's the box see, and he's opening the box.

Lea: Is that his mouth? No, his nose is there and his head is kind of like looking down. Okay I see it now. ((she is turning the page)) Oh wow, red shoes.

Darren: He's walking around in the red shoes.

Maria: That the person knitted.

Peter: I think it's a girl because they're like girls' shoes.

Maria: Yeah.

Darren: Yeah.

Lea: That's a bit of a generalisation comment, don't you think? They look like girls' shoes ((mocking)).

Before the children turn the page and see the red shoes, they refer to the character as if he is a boy. After they reveal the content of the box, Peter points out that "it's a girl", because the shoes are "like girls' shoes". The shoes are drawn like ballet pumps and the children interpret this kind of shoe fashion as typical for girls. Everyone agrees, with Lea's question being the only objection ("That's a bit of a generalisation comment, don't you think?"). Although Lea recognises a rational flaw in the argument of her classmates, her last few words and her laugh immediately cancel her previous deeper comment which could have triggered further discussion 
on gender identity. Perhaps this laugh reveals that she wants to lighten the tone of her comment to maintain the group's cohesion, in case her classmates think differently.

The children interpret the texts and by extension the matter of gender, from the point of view of their interpretive community (Fish, 1980). That is, their socio-cultural background, their age and gender, the environment in which they live, influence their interpretations. The ambiguity afforded by wordless picturebooks encourages them to reflect on gender identity, as without helpful pronouns to guide them, they have to look closer into the illustration and search for all those visual clues that can give them useful information about the characters' gender. Even though the pictures offer these children much space to ponder over gender representations and to even avoid strict characterisations, when it comes to the verbalisation of their thoughts, this space or gap gets significantly minimalised. They have to make instant decisions about their vocabulary and the use of the pronouns if they are going to talk about the characters in the context of a group discussion (these decisions would not be expressed if they were reading silently). In the Greek language especially, it is very difficult to refrain from specifying the gender, as articles, nouns and adjectives are all gender-bound.

As is evident from the data, gender was a matter of significant importance to the children when reading this book and they were unsettled by the gender ambiguity of the illustrations. They tried to use any clues in order to simply identify the figures and in turn, to build a sense of a character. However, the participants drew on some simplistic stereotypes and general assumptions which can be found in real life but can get disputed after critical reflection (e.g. colour as a gender signifier).

Whether the participants come from the Greek or English groups, their stereotypes on gender identity and its relationship to physical appearance and colours seem to be very similar and to determine the meaning-making process. Their responses might also be affected by their age and the mixed composition of the groups. In addition, although all groups make comments about characters' appearance, they do not thoroughly discuss characters' stereotypic behaviours. Instead, as we see in this subsection, both Greek and English Groups 2 seem to use laughter in the same spirit as described in Adelswärd's study (1989). That is, laughter serves as a means of socialisation; it helps to handle tensions caused by ambiguities or disagreements, to restore the dialogical balance and to achieve consensus or rapport.

\section{Personal Experiences}

From discussing the common general knowledge connections that the children make, I move on to the personal experiences that the children draw on as they respond to Caperucita Roja. These are life-to-text connections or, as Joyce Many and Diana Anderson argue (1992), autobiographical comments. At a rudimentary level, all connections come from the personal stories of the readers; what the children know, what they have learnt at school or in their daily interactions, how they interpret the ambiguities of the pictures, how culture affects their views. All of these seem to come from the children's personal backgrounds. This is why it is difficult to categorise children's personal experiences. However, the number of these 
references is relatively small, in comparison to the other categories described in this article. The children might want to relate personally with the text, but they do not express or might not be used to expressing these connections. It is also likely that I am not able to follow all these connections, as they can be less visible to someone who is not familiar with the personal life of each child. In the sequence below, English Group 2 reads Doublespread 17 of Caperucita Roja, in which the wolf's tail is depicted as being so big that it spreads across both pages and surrounds the grandmother's house:

\section{[English Group 2]}

Darren: It's like it's a spiral round the house, because that's the four paw prints where it's come in and then it'll come round.

[...]

Lea: ... and then like the shoulder area is bigger.

Darren: Yeah before you get to the neck, so it's like round -

Peter: And it's like more fluffy and like, because I had a cat and it was really fluffy around its neck.

Lea: It's like where its main organs are, so to keep it warm.

Peter: Yes, if you stroke just like, right there, it was quite fluffy.

Lea: This is completely irrelevant.

Maria: And then this shows how big its eyes are.

The children are impressed by the disproportioned figure of the wolf and therefore comment on the size, but also the texture of his body parts. Lawrence Sipe (2000, p. 78) talks about "verbal catalysts", specific words in a text which can spark intertextual connections. In this study, since there are no words in the wordless picturebooks, the term "visual catalysts" could replace Sipe's term. For example, in the above conversation, the fluffy tail of the wolf functions as a visual catalyst which suggests to Peter memories of his cat. Even though Peter explains the reason why he associates the wolf with his cat, this information does not support the children's collective meaning-making. Hence, Lea explicitly complains about how irrelevant Peter's words are in a tone that urges their classmates to return to the actual story of the book and not pay attention to Peter. Peter might have wanted to elaborate more on his personal story, but did not do so after Lea's intervention. According to Lea, the group has to stick to the reading task. From a socio-cultural perspective, the school setting might influence the readers and affect their interpretations: first, they may carry with them influences from the interpretive community of their classroom; second, being pupils, my readers would tend to follow certain school rules that directly affect their behaviour. Lea, for example, may have put such an abrupt end to Peter's story, because she might be aware that her group has to accomplish a school task, namely to read and interpret a story, and finds everything else irrelevant. Also, her stance could possibly be influenced by her teacher(s) who might not allow time for children's personal stories while they read in the classroom.

It is interesting that the examined groups embraced the task of reading wordless picturebooks with excitement, as something that they are not used to be doing in the classroom in terms of two aspects: discussions on images and discussions with no mediation that could lead to more personal connections. At the end of the research, 
three out of four groups actually asked me why they are not given similar activities more often - a point to take forward for further investigation and to raise teachers' awareness.

There are more personal responses in the data that seem subtly relevant to the book and also appear to be even simpler than the example described above, yet, despite their simplicity, they play an important role in children's engagement. Bleich (1975) argues that people think mostly about themselves and see the world in terms of themselves. This is what Sipe (2000, p. 271) calls the "personalising impulse". Thus, it comes naturally to say that when readers cannot make connections to their personal experiences and their common general knowledge, their engagement might be seriously impeded. Maria Ghiso and Caroline McGuire (2007), who describe young children's responses to picturebooks with sparse written text, emphasise the significance of connecting the story to readers' experiences as a way of building bridges between the picturebooks and the children's lives. Therefore, even though these connections might be short and relatively unsophisticated, they arise from the children's impulse and excitement to present a part of their selves in the discussion of the book. "Just because we cannot make sense of the connection[s] does not mean they [can]not" (Many and Anderson, 1992, p. 63). As simple as they seem to be for adults, they may be meaningful to children.

\section{Intertextual Connections}

When scholars of children's literature refer to texts in the concept of intertextuality, they go beyond the limits of written works and include pieces of art, films, videos, music, and so forth (Arizpe et al., 2014; Cairney, 1992; Pantaleo, 2007b; Sipe 2000, 2008a). That is, they refer to a mosaic of various experiences involving language and visual art that can be derived from the text (Sipe, 2008a). In my study, I argue that due to the polysemic and ambiguous essence of wordless picturebooks, the children's responses are teeming with intertextual references, some of which are more explicit than others. Apart from fairytales, which occupy most of the children's references and have already been discussed, in most cases the source of their intertextual allusions is books, video games, as well as films and TV products. What is more important than the medium, though, is the content of the children's intertextual connections. Two main themes emerged; narrative connections and visual connections.

The children's connections to style and to visual resemblances among figures fall into the category of "intervisuality", described by Maria Nikolajeva and Carole Scott as links between different pictures (2001, p. 228). What is common in the connections all groups make is that they do not support the children's creation of narrative. Instead, the children "freeze" the narrative, deviate from its linear path and concentrate on the juxtaposition of the visual and the intervisual. They are able then not only to return to the story, but also to turn the pages with more enthusiasm in the light of new possible links. However, the children's visual connections within this study did not present much depth or complexity. Through similes usually expressed with the word "like", the children name various visual texts, but they explain 
further neither the reasons behind their associations nor how these associations can be incorporated into the reading of the examined book. In Sipe's words, these similes are very "associative" with "an unelaborated statement of likeness" (2008a, p. 131). An example of an associative intervisual connection comes from Ophelia's enthusiastic remark (English Group 1) when she first encounters the picture of Little Red Riding Hood wearing the hat her grandmother gifted to her. Ophelia pauses the narration and very briefly draws a parallel between the heroine's enlarged round head and the British stop sign, probably because of their similar shape and colour.

On the other hand, when the groups refer to intertextual connections to narrative, they are more analytical; they discuss in more detail the similarities of the intertexts and how these connections can help the story unfold. This shows that these Greek and English children are capable of thinking more analytically and at the same time, it raises questions about the reasons why they seem superficial when it comes to visual links. Presumably, one of the reasons is that they are used to discussing verbal narratives at school but not pictures, as their teachers explained. Although they do not lack higher-order thinking skills, as evident from their intertextual connections and their transcripts in general, they might lack the vocabulary to describe artistic similarities and differences more thoroughly. As Judith Lysaker (2019, p. 11) argues while exploring "trasmediation", "reading images, and voicing their meanings in speech, requires translating meanings from one language mode to another". The metaphoric dialogue between the illustrator and the reader has to take specific form in a dialogue between real readers who read the same book together. This explains why making sense of pictures is different from discussing them with others. And sometimes the latter can be more complicated.

\section{Conclusion}

In the process of my primary text selection, initially I had doubts about the choice of Caperucita Roja. The age range of its suggested readership, as advertised on popular online bookshops, is three to six years. Despite the ambiguous and surreal nature of Perles' illustration which has the potential to invite sophisticated responses, this made me wonder if the examined children in the last grade of primary school would embrace the book or would quickly skim the images considering that it narrates a well-known fairytale better addressed to younger readers. The discussed case studies proved that not only did the book intrigue groups consisting of older children, but also brought to the fore ideas worth exploring further.

With no prompts to guide their conversations, both English and Greek groups drew on their common general knowledge, as they expected that the world of the books resembles the world they themselves live in. They all reproduced similar gender stereotypes, considering red as a girl's colour and associating particular clothes and accessories with a particular gender. Arguably, textual interpretations grounded in stereotypes should be investigated more, especially in the school environment, given the power that it has to promote a wide variety of views and enlightened ideas. Drawing on Rosenblatt (1965/1995), the more set an idea seems to be, the more attention needs to be drawn to it and the more questioned 
it should become by readers. Literature and wordless picturebooks in particular (which could favour ungendered representations themselves) have the potential to promote more critical and open-minded thinking, by assisting in acknowledging the complexity of gender identity and the diversity of gender roles as represented in fiction.

Additionally, the children within this study generated links to individual experiences from their personal lives. This highlights the ways in which wordless picturebooks can be powerful enough to engage older students and create longer-lasting relationships between the reader and the text, as the former infuses autobiographical elements into the latter.

When the groups made visual connections, based on the style of the images or visual resemblances among characters in the examined book and characters in other texts, their talk was very simplistic, though these links were also noteworthy. First, visual connections enriched the readers' collaborative spirit, as all children showed enthusiasm, especially while "identifying" together characters that looked familiar to them. Second, the reasons behind the simplicity of visual connections could possibly lie in the children's lack of knowledge of visual vocabulary. The findings show that fluency in the written code does not necessarily mean fluency in the visual code too. Although these children encounter visual stimuli in their daily life, they do not seem to be used to engaging in conversations that explore them further. English and Greek curricula often focus on verbal narratives, offering students fewer opportunities to discuss visual texts. However, this study indicates that the children have the ability to generate more elaborate responses which require advanced thinking skills, based upon their narrative connections. Teachers can play a significant role and help children find the words for expressing themselves concerning visual material. This need has been expressed by various researchers (Arizpe \& Styles, 2016; Farrell, Arizpe \& McAdam, 2010; Kiefer, 1995; Pantaleo, 2013; Sipe, 2008b), but without any reference to children's intertextual/intervisual connections which, as shown in this paper, can contribute to group discussion and the interpretation of books.

The absence of words and the prominence of illustrations gave the children the space and the opportunity to recall examples from their popular culture, such as Disney films, and The Eurovision Song Contest. There seems to be some prejudice on children's popular culture repertoire; it is not usually included in official educational contexts and thereby, teachers might be reluctant to foster links to it (Marsh and Millard, 2000). Reading Caperucita Roja without the help of teachers possibly allowed the participants to more freely bring this cultural fund of knowledge to their school environment and to show that it is a type of literacy they are interested in. An educator who listens to children's voices and tries to understand their reading experiences can get a better insight into their world and can connect more substantially with their cultural reference points.

The comparative elements of the study produced the seemingly conflicting finding that while the children's cultural connections played a key role in their interpretations of the wordless picturebook, the overall responses did, nonetheless, not differ considerably between children living in different cultural contexts. This was further emphasised by the lack of mediation by an educator that could 
have potentially added further country-specific cultural connotations and was enabled in the first instance by the wordless character of the book. By removing both linguistic factors and educational mediation it became possible to notice indications of the universal character of this type of book and its ability to transcend external cultural barriers in eliciting children's responses. When interacting on their own, the participants focused on the content of the stories, assigned their individual but shared meaning to them, and negotiated that with each other through communication on their own terms. They connected to the book and to each other in ways that were described above to be often unexpected and enhancing the argument for offering more agency to pupils when conducting research about their responses to literature. This would lead to a more coherent and holistic understanding not only of how they view books but also arguably of their views of the world. As Rita from English Group 1 pointed out, "it is nice to like actually discuss it with other people cause some people pointed things that [she] hadn't realised and then it kind of made you get everything because everybody is looking at different things". Rita's remark help us gain a deeper insight into her preferable process of reading wordless picturebooks, as well as her perspective on collaboration and sharing ideas.

By highlighting the variety of sixteen 11-year-old children's connections to a wordless picturebook, the present study also indicates that there might still be room for cultivating older students' reading diversity. That is, broadening their reading horizons and offering them opportunities to read and discuss wordless picturebooks. By assuming that some illustrations are too simple to read, teachers or parents who share books with children (or even publishers who assign age groups, as shown in the example of Caperucita Roja) could be at the risk of limiting older children's reading experiences and depriving them of potentially thought-provoking stories.

Funding This research was financially supported by the Onassis Foundation, and the Foundation for Education and European Culture (IPEP).

Consent for publication All pictures included in this article are reprinted by permission of the illustrator Pedro Perles.

Open Access This article is licensed under a Creative Commons Attribution 4.0 International License, which permits use, sharing, adaptation, distribution and reproduction in any medium or format, as long as you give appropriate credit to the original author(s) and the source, provide a link to the Creative Commons licence, and indicate if changes were made. The images or other third party material in this article are included in the article's Creative Commons licence, unless indicated otherwise in a credit line to the material. If material is not included in the article's Creative Commons licence and your intended use is not permitted by statutory regulation or exceeds the permitted use, you will need to obtain permission directly from the copyright holder. To view a copy of this licence, visit http://creativecommons.org/ licenses/by/4.0/.

\section{References}

Adelswärd, Viveka. (1989). Laughter and Dialogue: The Social Significance of Laughter in Institutional Discourse. Nordic Journal of Linguistics, 12(2), 107-136. 
Arizpe, Evelyn, Colomer, Teresa, and Martínez-Roldán, Carmen. (2014). Visual journeys through wordless narratives: An international inquiry with immigrant children and 'The Arrival'. London: Bloomsbury.

Arizpe, Evelyn, and Styles, Morag. (2016). Children reading picturebooks: Interpreting visual texts. Abingdon: Routledge.

Barthes, Roland. (1974). S/Z. Trans. Richard Miller. New York: Hill \& Wang.

Bassey, Michael. (1999). Case study research in educational setting. Buckingham: Open University Press.

Bleich, David. (1975). Readings and feelings: An introduction to subjective criticism. Illinois: National Council of Teachers of English.

Cairney, Trevor H. (1992). Fostering and building students' intertextual histories. Language Arts, 69(7), 502-507.

Crawford, Patricia A., and Hade, Daniel D. (2000). Inside the picture, outside the frame: Semiotics and the reading of wordless picture books. Journal of Research in Childhood Education, 15(1), 66-80.

Crisp, Thomas, and Hiller, Brittany. (2011). "Is this a boy or a girl?": Rethinking sex-role representation in Caldecott medal-winning picturebooks, 1938-2011. Children's Literature in Education, 42(3), 196-212.

Farrell, Maureen, Arizpe, Evelyn, and McAdam, Julie. (2010). Journeys across visual borders: Annotated spreads of 'The Arrival' by Shaun Tan as a method for understanding pupils' creation of meaning through visual images. Australian Journal of Language and Literacy, 33(3), 198-210.

Fish, Stanley. (1980). Is there a text in this class?: The authority of interpretive communities. Cambridge, Mass.: Harvard University Press.

Ghiso, Maria P., and McGuire, Caroline E. (2007). "I talk them through it": Teacher mediation of picturebooks with sparse verbal text during whole-class readalouds. Reading Research and Instruction, 46(4), 341-361.

Ghosh, Kerenza. (2015). Who's afraid of the big bad wolf: Children's responses to the portrayal of wolves in picturebooks. In Janet Evans (Ed.), Challenging and controversial picturebooks: Creative and critical responses to visual texts (pp. 201-224). Abingdon: Routledge.

Iordanaki, Evangelia (Lina). (2017). A socio-cultural study exploring Greek and English 11-year-old children's responses to wordless picturebooks (Doctoral thesis). University of Cambridge, UK.

Iser, Wolfgang. (1980). The act of reading: A theory of aesthetic response. London: The Johns Hopkins University Press.

John-Steiner, Vera, and Mahn, Holbrook. (1996). Sociocultural approaches to learning and development: A Vygotskian framework. Educational Psychologist, 31(3-4), 191-206.

Kiefer, Barbara Z. (1995). The potential of picture books: From visual literacy to aesthetic understanding. Columbus. OH: Merrill/Prentice Hall.

Kress, Gunther, and van Leeuwen, Theo. (2006). Reading images: The grammar of visual design, 2 nd ed. Abingdon: Routledge.

Lindauer, Shelley L. Knudsen. (1988). Wordless books: An approach to visual literacy. Children's Literature in Education, 19(3), 136-142.

Lysaker, Judith T. (2006). Young children's readings of wordless picture books: What's 'self' got to do with it? Journal of Early Childhood Literacy, 6(1), 33-55.

Lysaker, Judith T. (2019). Before words: Wordless picture books and the development of reading in young children. New York: Teachers College Press.

Lysaker, Judith T., and Hopper, Elizabeth. (2015). A Kindergartner's emergent strategy use during wordless picture book reading. The Reading Teacher, 68(8), 649-657.

Lysaker, Judith T., and Miller, Angela. (2013). Engaging social imagination: The developmental work of wordless book reading. Journal of Early Childhood Literacy, 13(2), 147-174.

Maine, Fiona, Cook, Victoria, and Lähdesmäki, Tuuli. (2019). Reconceptualizing cultural literacy as a dialogic practice. London Review of Education, 17(3), 383-392.

Many, Joyce E., and Anderson, Diana D. (1992). The effect of grade and stance on readers' intertextual and autobiographical responses to literature. Reading Research and Instruction, 31(4), 60-69.

Marsh, Jackie, and Millard, Elaine. (2000). Literacy and popular culture: Using children's culture in the classroom. London: SAGE Publications.

Nikolajeva, Maria, and Scott, Carole. (2001). How picturebooks work. Abingdon: Routledge.

Nodelman, Perry. (2005). Decoding the images: How picture books work. In P. Hunt (Ed.), Understanding children's literature, 2nd ed (pp. 128-139). Abingdon: Routledge. 
Pantaleo, Sylvia. (2007a). How could that be?: Reading Banyai's "Zoom" and "Re-Zoom". Language Arts, 84(3), 222-233.

Pantaleo, Sylvia. (2007b). Scieszka's The Stinky Cheese Man: A tossed salad of parodic re-versions. Children's Literature in Education, 38(4), 277-295.

Pantaleo, Sylvia. (2009). Exploring student response to contemporary picturebooks. Toronto: University of Toronto Press.

Pantaleo, Sylvia. (2013). Revisiting Rosenblatt's aesthetic response through 'The Arrival'. Australian Journal of Language and Literacy, 36(3), 125-134.

Perrault, Charles, and Perles, Pedro. (2010). Caperucita Roja. Alcalá la Real: Mil y un Cuentos.

Pinkney, Jerry. (2009). The lion and the mouse. New York: Hachette Book Group.

Reese, Colleen. (1996). Story development using wordless picture books. The Reading Teacher, 50(2), 172-173.

Rosenblatt, Louise M. (1965/1995). Literature as exploration. 5th edn.. New York: The Modern Language Association.

Rosenblatt, Louise M. (1978/1994). The reader, the text, the poem: The transactional theory of the literary work. 2nd edn. Carbondale and Edwardsville: Southern Illinois University Press.

Rosenblatt, Louise M. (1991). Literature-S. O. S.! Language Arts, 68(6), 444-448.

Rosenblatt, Louise M. (1994). The transactional theory of reading and writing. In Robert B. Ruddell, Martha Rapp Ruddell and Harry Singer (Eds.), Theoretical models and processes of reading ( $\mathrm{pp}$. 1057-1092). Newark, DE: International Reading Association.

Serafini, Frank. (2014a). Reading the visual: An introduction to teaching multimodal literacy. New York, Columbia: Columbia University.

Serafini, Frank. (2014b). Exploring Wordless Picture Books. The Reading Teacher, 68(1), 24-26.

Sipe, Lawrence R. (2000). The construction of literary understanding by first and second graders in oral response to picture storybook read-alouds. Reading Research Quarterly, 35(2), 252-275.

Sipe, Lawrence R. (2008a). Storytime: Young children's literary understanding in the classroom. New York: Columbia University.

Sipe, Lawrence R. (2008b). Young children's visual meaning making in response to picturebooks. In James Flood, Shirley Brice Heath and Diane Lapp (Eds.), Handbook of research on teaching literacy through the communicative and visual arts. New York: Lawrence Erlbaum Associates.

Tan, Shaun. (2004). Picture books: Who are they for? Shaun Tan's official website. Accessed 14 October 2013 from: https://www.shauntan.net/esssay-picture-books-who-for.

Tennent, Wayne. (2010). Understanding reading comprehension: Processes and practices. London: Sage. Thomas, Gary. (2013). How to do your research project. London: Sage.

Wiesner, David. (1991). Tuesday. New York: Clarion.

Wiesner, David. (2006). Flotsam. New York: Clarion.

Publisher's Note Springer Nature remains neutral with regard to jurisdictional claims in published maps and institutional affiliations. 